\title{
Bone metastases from lung cancer: a paradigm for multidisciplinary onco-rheumatology management
}

Cyrille B. Confavreux ${ }^{1-2}$, Jean-Baptiste Pialat ${ }^{2-3}$, Aurélie Bellière ${ }^{4}$, Marie Brevet ${ }^{5}$, Chantal Decroisette $^{6}$, Agnès Tescaru ${ }^{7}$, Julien Wegrzyn ${ }^{2-8}$, Cédric Barrey ${ }^{9-10}$, Françoise Mornex ${ }^{11-12}$, Pierre-Jean Souquet ${ }^{13}$, and Nicolas Girard ${ }^{14}$.

1) Centre Expert des Métastases et Oncologie Osseuse Secondaire -CEMOS, Service de Rhumatologie Sud, Hospices Civils de Lyon, 69310 Pierre Bénite FRANCE

2) Université de Lyon, INSERM UMR 1033-Lyos, 69008 Lyon FRANCE

3) Service de Radiologie Centre Hospitalier Lyon-Sud, Hospices Civils de Lyon, 69310 Pierre-Bénite, France

4) Centre Régional de Lutte Contre le Cancer Jean Perrin, 63000 Clermont Ferrand, France

5) Département d'Anatomopathologie, Groupement Hospitalier Est, Hospices Civils de Lyon, 69500 Bron, France

6) Centre Hospitalier Annecy-genevois, 1 boulevard de l'hôpital, 74370 Metz-Tessy, France.

7) Service de Médecine Nucléaire, Centre Hospitalier Lyon Sud, Hospices Civils de Lyon, 69310 Pierre-Bénite, France

8) Département de Chirurgie Orthopédique - Pavillon T, Hôpital Edouard Herriot, Hospices Civils de Lyon, 69003 Lyon, France

9) Département de Neurochirurgie et Chirurgie du Rachis- Université Claude Bernard Lyon I, Hôpital Pierre

Wertheimer, Hospices Civils de Lyon, 69500 Bron, France

10) Laboratoire de Biomécanique, ENSAM, Arts et Métiers Paris Tech, 75003 Paris, France

11) Département de Radiothérapie Oncologie, Centre Hospitalier Lyon Sud, Hospices Civils de Lyon, 69310

Pierre-Bénite, France

12) Université Claude Bernard Lyon1- EMR 3738, 69921 Oullins, France

13) Service de Pneumologie, Centre Hospitalier Lyon-Sud, Hospices Civils de Lyon, 69310 Pierre-Bénite, France

14) Université de Lyon, Université Claude Bernard Lyon 1, Lyon, France ; Institut du Thorax Curie Montsouris, Institut Curie, 75005 Paris, France

\section{Corresponding author :}

Dr Cyrille Confavreux, MD PhD

Centre Expert des Métastases et d'Oncologie Osseuse Secondaires (CEMOS)

Service de Rhumatologie

Centre Hospitalier Lyon Sud

165 Chemin du Grand Revoyet

69495 Pierre Bénite Cedex

T : 0478861231

Cyrille.confavreux@chu-lyon.fr

(C) 2018 published by Elsevier. This manuscript is made available under the CC BY NC user license

https://creativecommons.org/licenses/by-nc/4.0/ 


\section{Abstract}

Bone is the third metastatic site after liver and lungs. Bone metastases occur in one out of three lung cancers and are usually of osteolytic aspect. Osteolytic bone metastases are responsible of long bone and vertebral fractures leading to restricted mobility, surgery and medullar compression that severely alter quality of life and that have a huge medicoeconomic impact. In the recent years, Bone Metastatic Multidisciplinary Tumour Board (BM $\left.{ }^{2} \mathrm{~TB}\right)$ have been developed to optimize bone metastases management for each patient in harmony with oncology program. In this review, we will go through all the different aspects of bone metastases management including diagnosis and evaluation (CT scan, Tc 99m-MDP bone scan, ${ }^{18}$ FDG-PET scan and biopsy for molecular diagnosis), systemic bone treatments (zoledronic acid and denosumab) and local treatments (interventional radiology and radiotherapy). Surgical strategies will be discussed elsewhere. Based on the last 2017-Lung Cancer South East French Guidelines, we present a practical decision tree to help the physicians for decision making in order to reach a personalized locomotor strategy for every patient.

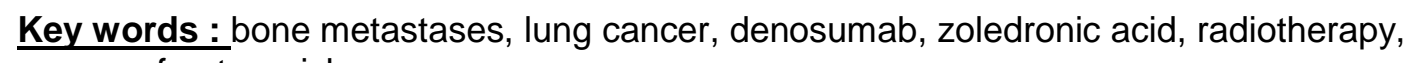
surgery, fracture risk 


\section{Introduction}

Bone metastases are made of tumour cells that left the primary tumour to localize into the bone tissue. These tumour cells derived from the primary tumour but have specific properties allowing 1) the journey from the primary site to bone including invasion, epithelial-tomesenchymal transition, or homing 2) and the settlement in the hostile environment of the bone. Once in the bone metastatic niche, tumour cells may remain for a long period in a dormant state with multiple interactions with the bone microenvironment and the different cells among which osteoblasts, osteoclasts, hematopoietic cells, immune cells and vessels [1]. Some cancers are more prone to disseminate to the bone such as breast, prostate, renal, thyroid and lung cancers. In these tumours, cells do not randomly disseminate but instead through a guided process named chemotactism. All these properties are currently under investigations around the world with the hope to uncover therapeutic targets that could be later used in humans. When tumour cells escape from dormancy, they locally disorganize to their own profit normal bone remodeling into a « vicious circle » that release growth factors and calcium $[2,3]$.

This vicious circle is at the origin of the observed patient symptoms. Indeed, bone metastases are responsible of a high morbidity - so-called skeletal related events (SRE) - in patients such as severe bone pain, hypercalcemia and in many cases local bone fragility leading to pathologic fractures of long bones and vertebrae with frequently medullar compression.

Lung cancer is the leading cause of cancer-related death worldwide [4] and bone metastases occur in more than one out of three [5] patients along the course of the disease. Up to now, patients with bone metastases from lung cancers experiment frequent SRE in line with the osteolytic aspect of the metastases and had a particularly severe prognosis with an overall median survival of 9 months [6]. Thus lung cancer perfectly illustrates the impact of considering simultaneously both bone metastasis care and oncological treatment, in a multidisciplinary setting. Meanwhile, lung cancer treatment and prognosis are drastically changing as ever with the onset of personalized medicine based on targeted agents, and the routine use of immunotherapies with checkpoint inhibitors.

This review relies on the clinical guidelines issued by the French South-East Lung Cancer Conference group (FSELCC) [7]. For sake of space and clarity, we deliberately decided to highlight some specific points to help physicians to manage bone metastases in lung cancer patients around 15 practical questions gathered into three major areas of bone metastases: the diagnosis, the systemic bone treatments and the local treatments. The bone metastases 
surgical specificities will be exposed in a different review. This focus serves as a paradigm for the global management of bone metastases from any cancer.

\section{Diagnosis: recent advance on extension evaluation and histology}

\subsection{Histology}

The vast majority of lung cancers encountered in symptomatic bone metastasis field are adenocarcinoma. Nevertheless, the old simple histological classification of lung cancer divided into small cell lung cancer (SCLC) and non-small cell lung cancer (NSCLC) gathering epidermoid and adenocarcinoma subtypes, has been completely updated with the progress of molecular biology and the development of molecular diagnosis in routine. Molecular profiling of tumour is currently a key issue to reach a personalized medicine approach targeting oncologic alteration such as EGFR mutations and ALK rearrangements. In many situations, biopsies of metastatic sites are preferred while access to the primary lung tumour is precluded by co-morbidities in smokers or technical issues. Moreover, bones metastases of lung adenocarcinoma are mostly located in the spine and the pelvis where bone biopsies are easily performed by trained radiologists under CT-scan [8].

\section{Question 1: Which bone location is the best for bone biopsy and how should tissue samples be processed?}

Selection of the target site is based on its cellular character, its accessibility and the impact of a potential local treatment such as cementoplasty for pain. It is awarded to target the border of the lesions, where tumour burden is the most active, in order to obtain multiple bone specimens and avoid necrosis. For tissular lytic lesions, bones sample from the edge of the lesion can lead to the diagnosis. Usually, two $1 \mathrm{~cm}$ biopsies (14G) are sufficient for histopathological and molecular diagnosis.

Bone biopsies have to be quickly immerged in formalin $10 \%$ for at minimum 6 hours. If necessary, bone decalcification has to be performed by EDTA (0.5M EDTA, (pH 8.0) Molecular Biology Grade) after fixation process. EDTA decalcification avoids the DNA hydrolysis observed with acid reagents contained in usual decalcification procedures and is quite short with these small specimens (less than $48 \mathrm{~h}$ depending of the calcification density). Specimen should be treated separately to perform immunohistochemistry - with a validation of the techniques on EDTA as a prerequisite - and molecular profiling. 


\section{Question 2: What is molecular diagnosis?}

Once diagnosis of lung adenocarcinoma is established, molecular genotyping - sequencing, next-generation sequencing, in situ hybridation - could be performed as recommended by standard guidelines for the management of NSCLC [9]. For best results, DNA extraction may be performed after laser microdissection in order to increase PCR sensitivity. All biomarkers should be investigated. Priority is done to EGFR mutations and ALK rearrangement in never or light smokers, and to PD-L1 expression in smokers since targeted therapies (tyrosine kinase inhibitors and immune therapies) are available. In case of treatment resistance, specific secondary mutations should also be investigated. In case of squamous cell carcinoma, PD-L1 expression should be evaluated. No biomarker has been recommended yet for the routine management of SCLC.

The POUMOS-TEC prospective project conducted in Lyon, France, has been the first one to describe the bone metastasis molecular pattern of patients with synchronous bone metastases from adenocarcinoma lung cancer [8]. In this study, a molecular diagnosis has been achieved in $96 \%$ of patients and nearly half of them presented a mutation. The most frequent mutations were KRAS (32\%) and EGFR (14\%). The prevalence of EGFR mutation was higher than expected from the prevalence observed in primary tumors. Krawczyk et al. also reported the feasibility of molecular diagnosis on bone metastases and presented a high prevalence, despite the small number of samples, of EGFR mutations in bone metastases [10]. By contrast $A L K$ translocations were rare. POUMOS data are consistent with the results of Doebele et al. showing that KRAS and EGFR mutations were more frequently found in bone metastases whereas $A L K$ translocation was more frequently observed in liver metastases [11]. EGFR mutation in bone metastases is associated with an improved survival as in primary tumor [12] whereas patients with KRAS mutated tumor had a poorer prognosis [13]. Currently that is no data on PDL1 expression in bone metastases from lung cancer. 


\subsection{Imaging techniques and nuclear medicine for diagnosis}

Lung cancer bone metastases have variable lytic, sclerotic or mixed pattern. Radiographs have limited sensitivity and cross-sectional imaging modalities are preferred to screen patients for bone metastases. CT scanner has good spatial resolution and is able to detect metastases earlier than standard radiographs, even on the basic thoraco-abdominal scan images. Nevertheless, PET/CT remains more sensitive [14]. When patients are treated, CT offers valuable evaluation of bone metastasis volume progression, stability or sometimes reossification. CT thus represents a valuable tool to assess bone strength and mechanical stability to help the decision if a specific treatment is required or not.

Magnetic Resonance Imaging (MRI) has higher sensitivity than CT to detect bone metastases. T1, T2 with fat suppression or STIR and post-enhanced gadolinium T1 weighted sequences present a nice contrast between tumor and background [15]. MRI allows the detection of smaller lesions, bone marrow infiltration and epidural space invasion by the tumor with potential neurologic compression. In addition, dynamic-enhanced MRI is actually tested to predict treatment response $[16,17]$. MRI scanning is usually restricted to axial skeleton or focused on a limb specific location based on clinical signs or other imaging modalities findings (radiographs, bone scan or CT), but whole-body MRI using diffusion weighted imaging (DWI) is emerging as a reliable technique to screen patients in metastatic bone disease [18]. Whole body MRI is a cost-effective alternative to 18FDG-PET/CT for staging patients with primary lung cancer [19].

Tc $99 \mathrm{~m}-\mathrm{MDP}$ bone scan is a common imaging procedure to diagnose bone metastases on the whole skeleton [20]. This imaging technique is widely available, and delivers a low irradiation (about $4 \mathrm{mSv}$ ) to patients. Tc 99m-MDP sticks to osteoid, bone-forming tissue. Findings will be presented in the next question.

\section{Question 3: What is the diagnosis performance of bone scan?}

Sensitivity to detect bone metastases is high, ranging from $62 \%$ to $99 \%$, as even a low bone involvement (around 5\%) is sufficient to capture MDP. Sensitivity is actually higher in osteoclerotic bone metastases, such as the ones from prostate cancer, than in highly osteolytic lesions from lung cancer [10]. Bone scan detects bone metastases earlier than standard radiographs. Bone scan is then a standard procedure in the pretherapeutic workup of patients with lung cancer presenting with bone-related symptoms.

Specificity of bone scan is low since fixation can be due to multiple disorders including osteoarthritis, primary bone diseases, infection, osteomalacia, fracture healing. Results 
should thus be interpreted in the light of clinical symptoms and radiographical aspect. Fused images obtained with single-photon emission computed tomography (SPECT) drastically improved localisation of the lesions and bone scan performances.

\section{Question 4: What is a "flare-up phenomenon" at bone scan?}

As highly osteolytic lesions are more frequent in lung cancer, initial bone scan may not detect some bone lesions at time of diagnosis, and fixation may appear after efficient anti-tumour therapy, leading to observe dissociation between responsive non-bone targets at whole body CT-scan and increased metabolism at bone scan. Fixation intensity observed at delayed phase is directly correlated to the tumour burden response and usually patients with the best response to anti-tumour therapy have increased intensity of bone scan fixations [21]. This early phenomenon called "flare-up phenomenon" corresponds to a hyperosteoblastic reaction during the bone formation activity recovery after the cancer cell destruction $[21,22]$. This should not be misunderstood as a tumour progression. The flare-up phenomenon has been reported with various malignant tumours such as osteosarcoma, lymphoma and lung, breast, or prostate cancers. A flare up phenomenon is observed in $15-30 \%$ of patients. There is no significant prognosis difference in good responder patients with or without flare up. Bone scan should not be performed before 6 months on therapy. When an early bone scan evaluation (before 6 months) is required, interpretation should be cautious and take into account clinical symptoms and radiological aspects. In blurred cases, MRI will show disappearance of tumour infiltration in bone.

\section{Question 5: What are the differences between bone scan and 18-FDG-PET for the assessment of bone metastases?}

The [18F]fluoro-D-glucose positron emission computed tomography (18-FDG PET-CT) corresponds to a direct way to detect glucosis influx in cells. Lung cancer cells have a particularly elevated glucose intake. Thus 18-FDG PET-CT has a high sensibility to detect lung cancer Mets in bone and soft tissue. To perform 18-FDG PET-CT examination is advised only for staging localized NSCLC [9]. This recommendation relies on several studies comparing bone scan and 18-FDG PET-CT in non-metastatic lung cancer. These studies showed that 18-FDG PET-CT has a higher sensibility and specificity than bone scan to detect bone metastases [23-28]. Nevertheless, in metastatic lung cancer, there is currently no recommendation to perform 18-FDG PET-CT instead of bone scan. Further studies are needed in bone metastatic setting to compare bone scan and 18-FDG PET-CT. 


\section{Systemic bone treatments of bone metastases}

\section{Question 6: What are the evidence for using bone antiresorptive drugs?}

The use of antiresorptive drugs aims at decreasing occurrence of bone events, improving quality of life and pain, and even survival $[29,30]$. Two drugs have been approved to treat bone metastases from lung cancer: zoledronic acid (ZOL) and denosumab (DMAB).

Bone events. The main study regarding ZOL in NSCLC is a phase III study published by Rosen which randomized 773 patients into three groups: placebo, ZOL 4mg/3 weeks and ZOL $8 \mathrm{mg} / 3$ weeks for 21 months [31]. The $8 \mathrm{mg}$ arm was discontinued because of renal safety without any superiority versus the $4 \mathrm{mg}$ arm. The 9 month intermediary report showed that ZOL reduced and delayed the risk of first bone event ( 230 days in the $4 \mathrm{mg}$ group versus 163 days with a HR at $0.732 p=0.017$ ) [32]. This was confirmed at 21 months (236 days versus 155 days $p=0.009$ ) with the following yearly incidence rates of 1.74 events per year on $4 \mathrm{mg} / \mathrm{month}$ versus 2.71 in the placebo group. Data for DMAB (120 mg/month $\mathrm{sc}$ ) are more recent and were obtained versus $\mathrm{ZOL}(4 \mathrm{mg} / \mathrm{month} \mathrm{iv})$ in a randomized (890 patients/group) double blind phase III study where $40 \%$ of the population had lung cancer [33]. Bone remodeling was more profoundly reduced by DMAB than ZOL (NTXu decreased by $76 \%$ versus $65 \%$ and alkaline phosphatases by $37 \%$ versus $29 \%$ ). Time of first bone event was delayed in the DMAB group compared to the ZOL one (20.6 versus 16.3 months respectively) with a decreased risk of $16 \%(\mathrm{HR}=0.84[0.71-0.98] \mathrm{p}=0.007)$. In the lung cancer subgroup (350 patients per group), the HR was not significant (0.84 [0.64-1.10]). Regarding tolerance, the rate of osteonecrosis of the jaw was similar in both groups (1.5\%); ZOL was responsible for more flu-like syndromes and DMAB for more hypocalcemia episodes.

Survival. Data concerning overall survival (OS) are scarce. Lipton et al. showed that the early normalization of bone resorption (NTXu) with ZOL in bone metastastic patients with initially a high level of remodeling, was associated with a survival improvement [34]. Nevertheless, the study by Rosen (ZOL vs placebo) failed to demonstrate an OS benefit [31,32]. Similarly the study by Henri (ZOL versus DMAB) found no difference in OS and progression free survival in the whole population [33]. Nevertheless, when focusing specifically on the lung cancer subgroup, the OS was significant $\mathrm{HR}=0.79$ [0.65-0.95]). Based on this result, an extension was conducted specifically in the lung cancer subgroup enriched by 60 additional patients (no bone events recorded) increasing the effective of each group to 400 in ZOL and 350 in DMAB) [35]. In this exploratory study, a benefit of OS in DMAB group was found (median survival 8.9 versus 7.7 months with an $H R=0.80$ [0.67-0.95] $p=0.05)$. The benefice was preserved in several subgroups such as patients with associated visceral metastases or adenocarcinoma/squamous cells. A randomized trial - SPLENDOUR -comparing first-line 
chemotherapy with or without DMAB, aiming at assessing OS, is currently ongoing, under the auspices of the European Thoracic Oncology Platform in patients with lung adenocarcinoma metastatic or not to the bone (NCT: NCT02129699).

In term of bone response, the treatment of osteolytic bone metastasis from EGFR mutated adenocarcinoma lung cancers by tyrosine kinase inhibitors has been associated with impressive fast and intense re-ossification of lytic lesions [36]. This re-ossification has certainly an impact on skeletal related events as reported by Sun et al. [37] who showed that the absence of use of tyrosine kinase EGFR inhibitor was associated with an increased risk of skeletal related event $(H R=1.9[1.4-2.6] p<0.001)$ and a shorter time to SRE (median of 3.3 vs $11 ; 8$ months). One explanation was that tumoral enzymes such as MMP and ADAMTS release EGF-like factors from the cell surface that will act on osteoblasts and decrease osteoprotegerin thus increasing osteolysis [38]. In vivo and in humans there is a synergy of action on osteolytic bone metastasis from EGFR mutated adenocarcinoma lung cancer between EGFR tyrosine kinase and antiresorptive drugs $[39,40]$.

\section{Question 7: When an antiresorptive drug should be initiated?}

There is no clear answer to the question if antiresorptive drugs should be initiated as soon as bone metastases appear or only once it has become symptomatic. It is clear that a patient with a first bone event is at increased risk of a second one in a short period of time $[31,41,42]$. Thus, initiation of an antiresorptive treatment (either $4 \mathrm{mg} / \mathrm{month}$ IV of ZOL for normal renal function or $120 \mathrm{mg} /$ month SC of DMAB) is recommended once a bone event occurs considering the expected benefit in terms of quality of life, pain limitation, hypercalcemia reduction and prevention of a secondary bone event. Current international guidelines in lung cancer advice the introduction of antiresorptive drugs at bone metastatic stage without specification on symptomatic status of the patient $[9,43]$.

\section{Question 8: What precautions should be taken before starting an antiresorptive drug?}

Since the use of antiresorptive treatment in profound vitamin $D$ deficient patients exposes to severe hypocalcaemia, all studies using antiresorptive drugs conducted in malignant osteolysis included calcium-vitamin D supplementation. Thus, it is necessary to search and fix a vitamin $D$ deficiency before initiation [44]. The target concentration of vitamin $D$ is superior to $30 \mathrm{ng} / \mathrm{ml}(75 \mathrm{nmol} / \mathrm{l})$. After, the daily recommended intakes are 800 of vitamin D/day and 1000-1200 mg/day of calcium for an adult.

In addition, it is also necessary to check renal function and perform dental examination prior initiation. Except in case of emergency, mouth restoration should be performed when necessary. In case of tooth extraction, antiresorptive treatment will be postponed until wound 
healing assessed by the dentist. On therapy, bi-annual dental follow-up is recommended. Dental extractions would be avoided as much as possible and conservative treatment favored [45] .

\section{Question 9: What is the duration of treatment?}

Beyond the 2 years of monthly treatment [31,33], there is no data in literature about the duration of ZOL or DMAB in bone metastatic patients from lung cancer; this was related to the historically short OS of patients, that now needs to be revisited with the prolonged efficacy of new antitumour approaches, including targeted therapies and immunotherapy. Alongside, the incidence rate of jaw osteonecrosis sharply increases after 24 months [46]. Therefore, it is recommended after two years of treatment to evaluate the benefit/risk of each patient depending on various parameters such as bone status, age, prognosis, previous fracture, radiological aspect and bone remodeling $[47,48]$. By contrast to bisphosphonate, DMAB is a biologic with no inertia [49] and a good compliance is warranted. The fact that in osteoporosis after DMAB discontinuation a bone remodeling rebound is observed [50], suggests that bone turnover markers should be monitored after DMAB discontinuation in bone metastasis setting. Awaiting results of studies regarding regimen after DMAB discontinuation, it may be proposed as an option to deliver a unique infusion of ZOL 3 months after discontinuation and a regular follow-up by bone oncologist. 


\section{Local treatments of bone metastases}

\subsection{Interventional radiology}

\section{Question 10: What are the percutaneous techniques available?}

Percutaneous local treatment nowadays belongs to the therapeutical arsenal in bone metastases of lung cancer, along the medical treatment, radiotherapy and surgery. One additional advantage is that it may be combined with a biopsy for histopathological and molecular diagnosis. Percutaneous treatments include cementoplasty, kyphoplasty or other expandable materials, percutaneous radiofrequency and cryoablation destruction techniques. These techniques may be combined if indicated and sometimes associated with percutaneous screw or locked nail fixation to fix bone fragility [51]. A personalized decision will be discussed during bone metastatic multidisciplinary tumor board involving radiologists, rheumatologists, oncologists, radiotherapists, orthopedists and pain management specialists. The bone lesion will have first to be adjudicated as responsible for the clinical signs by combination of patient interview, clinical examination and imaging data. It is crucial to consider related pain, stability and location of the lesion and the proximity of "at risk structures" such as nervous system and medulla mainly, but also joints, vessels or other organs to determine the scheme to be adopted, and balance the potential impact of the treatment in terms of risk and benefit compared to radiotherapy or surgical alternative. In several cases, percutaneous procedures can be combined to radiotherapy or surgery, always pondered in the perspective of the patient's survival time.

\section{Question 11: What are the indications and counter-indications for local percutaneous treatments?}

Cementoplasty allows rapid pain relief in about $80 \%$ of cases [32], even if the complete filling of the lesion is not achieved [52]. It is a good indication when patients are not controlled by analgesic drugs or encounter poor tolerance of the opioid treatment, especially in vertebral metastasis stable enough not to require surgical treatment, but with a benefit of stabilization using cement filling. Kyphoplasty and other techniques with expandable materials are preferred when vertebral height can be restored, or in conditions where the risk of leakage must be limited (large disruption of the posterior wall for instance). Cementoplasty can be used as well in long bone lesions, but mechanical properties of the cement do not allow sufficient solidity in bending or torsional stress. Thus treatment of bone metastasis at high risk of fracture implies the association of cementoplasty with percutaneous fixation technique, and is chosen when surgical fixation technique cannot be performed -4 patients 
among the 12 had a lung cancer [53]. Acetabular cementoplasty represents a good alternative to heavier surgical method to fill lytic lesion and restore mechanical conditions able to relieve pain in a standing position [54].

Percutaneous thermal ablation techniques (radiofrequency and cryoablation) allow controlling small bone metastasis or reducing the volume of large metastases hardly accessible to surgery or radiotherapy. It offers pain relief for metastases with large extent in soft-tissue where stabilization is not needed.

Eventually, combination of cementoplasty with percutaneous thermal ablation or other local methods such as analgesic radiotherapy may be decided in multidisciplinary board for immediate antalgic and stabilization [51]. Figure 1 shows an example of percutaneous bone metastasis ablation performed by initial cryotherapy secondarily completed by radiotherapy. A volume is destroyed around the active portion of the needle that is placed under CT-scan guidance in the metastasis. This allows for tumour control or reduction depending on the size of the tumour and the surrounding structures that must be preserved. Here an immediate (within 24 hours) relief has been obtained as also reported by others in $70 \%$ to $90 \%$ for radiofrequency and more than $75 \%$ for cryotherapy [34].

A summary of the main indications and counter-indications of the different percutaneous treatments are presented in table 1.

\section{Question 12: What are the adverse events of local percutaneous treatments?}

The hemorrhagic complications are rare, depending on the treatment site and especially on the ground.

The infectious complications are rare but dreadful because the cement is regarded as a materiel on which germs could attach. So, it may be covered by an antibiotic prophylaxis as it is often an immunocompromised ground.

The main dread complication of cementoplasty is the cement leak, more frequent than during the cementation for osteoporotic fractures [55] because it is difficult to predict its spread inside the tumour at the moment of injection. The cement is thick when injected in order to limit the vascular leaks (even embolism) and epidural leaks in the vertebrae (with the implied risk of radicular or medullary compression). The discal or extraosseous leaks inside the soft parts are quite frequent. Most of them are asymptomatic but some of them can be transitorily responsible for severe hyperalgesia.

Cementoplasty can consolidate vertebra, pelvic and flat bones, but is not able to resist to bending or twisting forces. Thus, consolidation of long bones needs to be very cautious, often associated with nails, wires or screws. 
Radiofrequency ablation using monopolar technique can generate electric arc when the electrode is placed near a metal implant, and is contraindicated when the patient has an implanted electronic device.

The major risk of thermal ablation is the injury of a structure adjacent to the lesion, like nerve, cartilage or skin.

\subsection{Radiotherapy}

$\mathrm{RT}$ is an essential tool in treatment of bone metastases. The French Society of Radiotherapy (SFRO) has recently up-dated its recommendations for bone metastases [56]. The aim of RT is to kill tumour cells but its efficacy depends on histology. Indeed, some tumours, such as renal cancer, are radioresistant. By contrast lung cancers offer an excellent radiosensibility. $\mathrm{RT}$ also favors bone regeneration. It is estimated that RT allows re-ossification in 65 to $85 \%$ of osteolytic lesions contributing to a differed stabilization within 3 to 6 months. Thus a local contention such a rigid corset or unloading may be useful to prevent immediate fracture risk.

\section{Question 13: What are the indications of radiotherapy?}

There are five different clinical indications of RT.

1) Treatment of uncontrolled bone pain.

2) Delayed fracture risk prevention.

3) Treatment of spinal cord compression. RT is commonly used alone in emergency or after surgery in case of spinal cord compression [57,58]. The Rades score may be useful to decide management [59] but relies on basic histology that has considerably evolved with molecular classification of the tumour.

4) Adjuvant post-operative RT. Radiation therapy is systematically prescribed 2 or 3 weeks after surgery, on healed wound to treat the microscopic disease. This strategy reduces local recurrence, rate of second surgery and the onset of pain syndrom.

5) Ablative strategy on solitary/oligo bone metastases. This clinical situation is uncommon and use a high dose of radiation delivered for vertebrae by stereotaxy. It could be discussed in patients with 1 to 3 bone metastases and a controlled primary tumour without any other metastases [60-62].

\section{Question 14: What is the optimal radiotherapy regimen?}

The current standard is a fractioned scheme of $30 \mathrm{~Gy}$ in 10 fractions which provides the best results in terms of duration of antalgic response, rate of second irradiation, bone reconstruction [63] and toxicities. Usually RT is delivered using 3D conformation technic. For

long bones, the whole pathological bone and the surgical material are included in the 
treatment fields. For vertebrae, the fields should include one vertebral body above and below the tumoral target except in case of epiduritis where the two adjacent vertebrae above and below the target should be irradiated. Laterally, bilateral pedicles and transverse processes should be included in the radiation field.

Single 8 Gy fraction could also be used. It allows a fast management with less mobilization and journeys for the patient, shorter impact on the global oncological treatment and is economically favorable. Immediate pain relief is equivalent to fractionated regimen but single fraction has been associated with more frequent second irradiation for pain $(20 \%$ for 8 Gy fraction vs $8 \%$ for fractionated regimen) [64]. Thus currently, single fraction regimen remains an optional strategy discussed for long bone irradiation and location with no at risk organ.

\section{Question 15: What is the optimal schedule between radiotherapy and systemic oncological treatment?}

The same day performance of radiation therapy and systemic oncological treatment in the management of palliative bone metastasis may not be indicated. The patient personalized schedule will depend on his global PS, the absence or not of at risk organ (e.g. intestine, spine) in the radiation field and the radiosensibility of the product. Risks of concomitance radiation therapy with systemic oncological treatments (chemotherapy, targeted therapy) are virtually not well known. Acute radiosensibilisation or recall phenomenon can be serious. In theory, a wash-out of 5 half-life time of systemic product has to be respected before the first day of radiation therapy. Currently, there are three drug profiles:

- systemic therapy with a high risk of radiosensibilisation where a wash out period has to be respected to avoid severe toxicities;

-systemic therapy compatible with palliative radiation therapy;

- and systemic therapy with few or no available data where precautionary principles and expert consensus should be applied. The SFRO has recently published expert guidelines for these 3 profiles [65]. Table 2.

Interaction between radiotherapy and immune checkpoint inhibitors remains a matter of preclinical and clinical investigation, regarding safety and efficacy, with reported occurrence of abscopal effect after the radiation of a single metastatic lesion. The current clinical practical window is seven days of interruption before and after radiotherapy except in case of emergency. The ongoing clinical trial NirvanaLung will study in its secondary endpoints tolerance of concomitant radiation and nivolumab treatment in stage III/IV NSCLC. 


\section{Toward an integrative approach of bone metastases management}

Bone metastases benefit from a comprehensive integrative management taking into account the global oncological strategy and the management of bone metastases. The initial step is to obtain the extension of the different locations and the following global oncological information: the kinetic and the histology of the tumour, the patient life expectancy and the toxicity obligations set by the oncological treatment. The next step is to assess for each bone location: pain, chronology of signs (acute vs chronic), the neurological consequences such as palsy, the adjacent organs (spinal cord, gut, lungs) and fracture risk. Precise fracture risk evaluation remains quite difficult. Some scores such as Mirels for long bones $[66,67]$ and Spinal Instability Neoplastic Score (SINS) [68] for vertebrae have been proposed to help evaluation of bone metastatic strength impairment and management based on RT and/or preventive orthopedic surgery. Table 3 and 4. They remain insufficient. Development of these scores, their clinical use including advantages and disadvantages will be reviewed in details in the review concerning the surgery of bone metastasis.

This basal evaluation will allow proposing a personalized schedule for each patient using pain and bone systemic treatments and local treatments as previously described. This is the additive value of the transversal Bone Metastatic Multidisciplinary Tumour Board $\left(\mathrm{BM}^{2} \mathrm{~TB}\right)$ performed in harmony with the Multidisciplinary Tumour Board (MTB) of the patient. Figure 2. Molecular diagnosis of the tumour, new targeted therapies, immunotherapies, and emerging tools to assess bone metastases strength will lead in the near future to more precise algorithms for bone metastasis management.

\section{Acknowledgments}

We are very thankful to Sébastien Couraud, ARISTOT association, Lecancer website team who organize the annually French South East Lung Cancer Guidelines meeting and the French Reviewer Comity of the Auvergne Rhone-Alpes -AURA- Lung Cancer 2017 Guidelines [Appendix A, Supplemental 1; See the supplementary material associated with this article online].

\section{Conflict of interests}

$A B, A T, C B, J B P, J W, F M, M B$, declare no conflict of interest. CC declares lectures for AMGEN, CELLGEN and BMS. CD, NG and PJS declare consultancy for AMGEN. 


\section{Appendix A. Supplementary data}

Supplementary data (Supplemental 1) associated with this article can be found in the online version at ... 


\section{Références}

[1] Chiang AC, Massagué J. Molecular basis of metastasis. N Engl J Med 2008;359:2814-23.

[2] Ell B, Kang Y. SnapShot: Bone Metastasis. Cell 2012;151:690-690.e1.

[3] Clezardin P. Pathophysiology of bone metastases from solid malignancies. Joint Bone Spine 2017;84:677-684.

[4] Jemal A, Bray F, Center MM, Ferlay J, Ward E, Forman D. Global cancer statistics. CA Cancer J Clin 2011;61:69-90.

[5] Coleman RE. Clinical features of metastatic bone disease and risk of skeletal morbidity. Clin Cancer Res Off J Am Assoc Cancer Res 2006;12:6243s-6249s.

[6] Decroisette C, Monnet I, Berard H, Quere G, Le Caer H, Bota S, et al. Epidemiology and treatment costs of bone metastases from lung cancer: a French prospective, observational, multicenter study (GFPC 0601). J Thorac Oncol Off Publ Int Assoc Study Lung Cancer 2011;6:576-82.

[7] Confavreux C, Barrey C, Belliere A, Decroisette C, Mornex F, Pialat J-B, et al. [Guidelines on Bone Metastases: 2017Update]. ARISTOT; 2017 [French]. n.d.

[8] Confavreux CB, Girard N, Pialat J-B, Bringuier P-P, Devouassoux-Shisheboran M, Rousseau J-C, et al. Mutational profiling of bone metastases from lung adenocarcinoma: results of a prospective study (POUMOS-TEC). BoneKEy Rep 2014;3:580.

[9] Novello S, Barlesi F, Califano R, Cufer T, Ekman S, Levra MG, et al. Metastatic non-small-cell lung cancer: ESMO Clinical Practice Guidelines for diagnosis, treatment and follow-up. Ann Oncol Off J Eur Soc Med Oncol 2016;27:v1-27.

[10] Krawczyk P, Nicoś M, Ramlau R, Powrózek T, Wojas-Krawczyk K, Sura S, et al. The incidence of EGFR-activating mutations in bone metastases of lung adenocarcinoma. Pathol Oncol Res POR 2014;20:107-12.

[11] Doebele RC, Lu X, Sumey C, Maxson DA, Weickhardt AJ, Oton AB, et al. Oncogene status predicts patterns of metastatic spread in treatment-naive nonsmall cell lung cancer. Cancer 2012;118:4502-11.

[12] Chambard L, Girard N, Ollier E, Rousseau J-C, Duboeuf F, Carlier M-C, et al. Bone, muscle, and metabolic parameters predict survival in patients with synchronous bone metastases from lung cancers. Bone 2018;108:202-9.

[13] Lohinai Z, Klikovits T, Moldvay J, Ostoros G, Raso E, Timar J, et al. KRAS-mutation incidence and prognostic value are metastatic site-specific in lung adenocarcinoma: poor prognosis in patients with KRAS mutation and bone metastasis. Sci Rep 2017;7:39721.

[14] Mitchell MD, Aggarwal C, Tsou AY, Torigian DA, Treadwell JR. Imaging for the Pretreatment Staging of Small cell Lung Cancer: A Systematic Review. Acad Radiol 2016;23:1047-56.

[15] deSouza NM, Liu Y, Chiti A, Oprea-Lager D, Gebhart G, Van Beers BE, et al. Strategies and technical challenges for imaging oligometastatic disease: Recommendations from the European Organisation for Research and Treatment of Cancer imaging group. Eur J Cancer 2018;91:15363.

[16] Kim HS, Yoon YC, Kwon S, Lee JH, Ahn S, Ahn HS. Dynamic Contrast-enhanced MR Imaging Parameters in Bone Metastases from Non-Small Cell Lung Cancer: Comparison between Lesions with and Lesions without Epidermal Growth Factor Receptor Mutation in Primary Lung Cancer. Radiology 2017;284:815-23.

[17] Zhang R, Wang Z-Y, Li Y-H, Lu Y-H, Wang S, Yu W-X, et al. Usefulness of dynamic contrastenhanced magnetic resonance imaging for predicting treatment response to vinorelbinecisplatin with or without recombinant human endostatin in bone metastasis of non-small cell lung cancer. Am J Cancer Res 2016;6:2890-900. 
[18] Blackledge MD, Tunariu N, Orton MR, Padhani AR, Collins DJ, Leach MO, et al. Inter- and IntraObserver Repeatability of Quantitative Whole-Body, Diffusion-Weighted Imaging (WBDWI) in Metastatic Bone Disease. PloS One 2016;11:e0153840.

[19] Usuda K, Funazaki A, Maeda R, Sekimura A, Motono N, Matoba M, et al. Economic Benefits and Diagnostic Quality of Diffusion-Weighted Magnetic Resonance Imaging for Primary Lung Cancer. Ann Thorac Cardiovasc Surg Off J Assoc Thorac Cardiovasc Surg Asia 2017;23:275-80.

[20] Pfister DG, Johnson DH, Azzoli CG, Sause W, Smith TJ, Baker S, et al. American Society of Clinical Oncology treatment of unresectable non-small-cell lung cancer guideline: update 2003. J Clin Oncol Off J Am Soc Clin Oncol 2004;22:330-53.

[21] Pluquet E, Cadranel J, Legendre A, Faller MB, Souquet PJ, Zalcman G, et al. Osteoblastic reaction in non-small cell lung carcinoma and its association to epidermal growth factor receptor tyrosine kinase inhibitors response and prolonged survival. J Thorac Oncol Off Publ Int Assoc Study Lung Cancer 2010;5:491-6.

[22] Krüger S, Buck AK, Mottaghy FM, Hasenkamp E, Pauls S, Schumann C, et al. Detection of bone metastases in patients with lung cancer: $99 \mathrm{mTc}-\mathrm{MDP}$ planar bone scintigraphy, $18 \mathrm{~F}-$ fluoride PET or 18F-FDG PET/CT. Eur J Nucl Med Mol Imaging 2009;36:1807-12.

[23] Bury T, Barreto A, Daenen F, Barthelemy N, Ghaye B, Rigo P. Fluorine-18 deoxyglucose positron emission tomography for the detection of bone metastases in patients with non-small cell lung cancer. Eur J Nucl Med 1998;25:1244-7.

[24] Cheran SK, Nielsen ND, Patz EF. False-negative findings for primary lung tumors on FDG positron emission tomography: staging and prognostic implications. AJR Am J Roentgenol 2004;182:1129-32.

[25] Devaraj A, Cook GJR, Hansell DM. PET/CT in non-small cell lung cancer staging-promises and problems. Clin Radiol 2007;62:97-108.

[26] Gayed I, Vu T, Johnson M, Macapinlac H, Podoloff D. Comparison of bone and 2-deoxy-2[18F]fluoro-D-glucose positron emission tomography in the evaluation of bony metastases in lung cancer. Mol Imaging Biol MIB Off Publ Acad Mol Imaging 2003;5:26-31.

[27] Min J-W, Um S-W, Yim J-J, Yoo C-G, Han SK, Shim Y-S, et al. The role of whole-body FDG PET/CT, Tc 99m MDP bone scintigraphy, and serum alkaline phosphatase in detecting bone metastasis in patients with newly diagnosed lung cancer. J Korean Med Sci 2009;24:275-80.

[28] Song JW, Oh Y-M, Shim T-S, Kim WS, Ryu J-S, Choi C-M. Efficacy comparison between (18)F-FDG $\mathrm{PET} / \mathrm{CT}$ and bone scintigraphy in detecting bony metastases of non-small-cell lung cancer. Lung Cancer Amst Neth 2009;65:333-8.

[29] Coleman RE, Lipton A, Roodman GD, Guise TA, Boyce BF, Brufsky AM, et al. Metastasis and bone loss: advancing treatment and prevention. Cancer Treat Rev 2010;36:615-20.

[30] Coleman R, Gnant M, Morgan G, Clezardin P. Effects of bone-targeted agents on cancer progression and mortality. J Natl Cancer Inst 2012;104:1059-67.

[31] Rosen LS, Gordon D, Tchekmedyian NS, Yanagihara R, Hirsh V, Krzakowski M, et al. Long-term efficacy and safety of zoledronic acid in the treatment of skeletal metastases in patients with nonsmall cell lung carcinoma and other solid tumors: a randomized, Phase III, double-blind, placebo-controlled trial. Cancer 2004;100:2613-21.

[32] Rosen LS, Gordon D, Tchekmedyian S, Yanagihara R, Hirsh V, Krzakowski M, et al. Zoledronic acid versus placebo in the treatment of skeletal metastases in patients with lung cancer and other solid tumors: a phase III, double-blind, randomized trial--the Zoledronic Acid Lung Cancer and Other Solid Tumors Study Group. J Clin Oncol Off J Am Soc Clin Oncol 2003;21:3150-7.

[33] Henry DH, Costa L, Goldwasser F, Hirsh V, Hungria V, Prausova J, et al. Randomized, doubleblind study of denosumab versus zoledronic acid in the treatment of bone metastases in patients with advanced cancer (excluding breast and prostate cancer) or multiple myeloma. J Clin Oncol Off J Am Soc Clin Oncol 2011;29:1125-32. 
[34] Lipton A, Cook R, Saad F, Major P, Garnero P, Terpos E, et al. Normalization of bone markers is associated with improved survival in patients with bone metastases from solid tumors and elevated bone resorption receiving zoledronic acid. Cancer 2008;113:193-201.

[35] Scagliotti GV, Hirsh V, Siena S, Henry DH, Woll PJ, Manegold C, et al. Overall survival improvement in patients with lung cancer and bone metastases treated with denosumab versus zoledronic acid: subgroup analysis from a randomized phase 3 study. J Thorac Oncol Off Publ Int Assoc Study Lung Cancer 2012;7:1823-9.

[36] Garfield D. Increasing osteoblastic lesions as a manifestation of a major response to gefitinib. J Thorac Oncol Off Publ Int Assoc Study Lung Cancer 2006;1:859-60.

[37] Sun J-M, Ahn JS, Lee S, Kim JA, Lee J, Park YH, et al. Predictors of skeletal-related events in nonsmall cell lung cancer patients with bone metastases. Lung Cancer Amst Neth 2011;71:89-93.

[38] Lu X, Wang Q, Hu G, Van Poznak C, Fleisher M, Reiss M, et al. ADAMTS1 and MMP1 proteolytically engage EGF-like ligands in an osteolytic signaling cascade for bone metastasis. Genes Dev 2009;23:1882-94.

[39] Canon J, Bryant R, Roudier M, Osgood T, Jones J, Miller R, et al. Inhibition of RANKL increases the anti-tumor effect of the EGFR inhibitor panitumumab in a murine model of bone metastasis. Bone 2010;46:1613-9.

[40] Zhang G, Cheng R, Zhang Z, Jiang T, Ren S, Ma Z, et al. Bisphosphonates enhance antitumor effect of EGFR-TKIs in patients with advanced EGFR mutant NSCLC and bone metastases. Sci Rep 2017;7:42979.

[41] Hirsh V, Tchekmedyian NS, Rosen LS, Zheng M, Hei Y-J. Clinical benefit of zoledronic acid in patients with lung cancer and other solid tumors: analysis based on history of skeletal complications. Clin Lung Cancer 2004;6:170-4.

[42] Lipton A. Treatment of bone metastases and bone pain with bisphosphonates. Support Cancer Ther 2007;4:92-100.

[43] De Marinis F, Eberhardt W, Harper PG, Sureda BM, Nackaerts K, Soerensen JB, et al. Bisphosphonate use in patients with lung cancer and bone metastases: recommendations of a European expert panel. J Thorac Oncol Off Publ Int Assoc Study Lung Cancer 2009;4:1280-8.

[44] Benhamou C-L, Souberbielle J-C, Cortet B, Fardellone P, Gauvain J-B, Thomas T. La vitamine D chez l'adulte : recommandations du GRIO 2011;40:673-682.

[45] Demoersman J, Soueidan A, Corre P, Pers JO. [Managing patients with therapeutic antibodies in odontostomatology]. Rev Stomatol Chir Maxillo-Faciale Chir Orale 2014;115:152-63.

[46] Facon T, Bensadoun R-J, Blanc J-L, Confavreux C, Gourmet R, Maes J-M, et al. [Osteonecrosis of the jaw and bisphophonates in oncology]. Bull Cancer (Paris) 2008;95:413-8.

[47] Aapro M, Abrahamsson PA, Body JJ, Coleman RE, Colomer R, Costa L, et al. Guidance on the use of bisphosphonates in solid tumours: recommendations of an international expert panel. Ann Oncol Off J Eur Soc Med Oncol ESMO 2008;19:420-32.

[48] Brantus J-F, Roemer-Becuwe C, Cony-Makhoul P, Salino S, Fontana A, Debourdeau P, et al. Guide de recommandations d'utilisation des bisphosphonates dans les lésions osseuses malignes des tumeurs solides et du myélome multiple. Rev Médecine Interne 2011;32:494-505.

[49] Bone HG, Bolognese MA, Yuen CK, Kendler DL, Miller PD, Yang Y-C, et al. Effects of denosumab treatment and discontinuation on bone mineral density and bone turnover markers in postmenopausal women with low bone mass. J Clin Endocrinol Metab 2011;96:972-80.

[50] Miller PD, Bolognese MA, Lewiecki EM, McClung MR, Ding B, Austin M, et al. Effect of denosumab on bone density and turnover in postmenopausal women with low bone mass after long-term continued, discontinued, and restarting of therapy: a randomized blinded phase 2 clinical trial. Bone 2008;43:222-9.

[51] Laredo J-D, Chiras J, Kemel S, Taihi L, Hamze B. Vertebroplasty and interventional radiology procedures for bone metastases. Jt Bone Spine 2018;85:191-9. 
[52] Cotten A, Dewatre F, Cortet B, Assaker R, Leblond D, Duquesnoy B, et al. Percutaneous vertebroplasty for osteolytic metastases and myeloma: effects of the percentage of lesion filling and the leakage of methyl methacrylate at clinical follow-up. Radiology 1996;200:525-30.

[53] Mavrovi E, Pialat J-B, Beji H, Kalenderian A-C, Vaz G, Richioud B. Percutaneous osteosynthesis and cementoplasty for stabilization of malignant pathologic fractures of the proximal femur. Diagn Interv Imaging 2017;98:483-9.

[54] Cotten A, Demondion X, Boutry N, Cortet B, Chastanet P, Duquesnoy B, et al. Therapeutic percutaneous injections in the treatment of malignant acetabular osteolyses. Radiogr Rev Publ Radiol Soc N Am Inc 1999;19:647-53.

[55] Laredo JD, Hamze B. Complications of percutaneous vertebroplasty and their prevention. Skeletal Radiol 2004;33:493-505.

[56] Thureau S, Vieillard M-H, Supiot S, Lagrange J-L. [Radiotherapy of bone metastases]. Cancer Radiother J Soc Francaise Radiother Oncol 2016;20 Suppl:S227-234.

[57] Schultheiss TE. The radiation dose-response of the human spinal cord. Int J Radiat Oncol Biol Phys 2008;71:1455-9.

[58] Rades D, Huttenlocher S, Bajrovic A, Karstens JH, Adamietz IA, Kazic N, et al. Surgery followed by radiotherapy versus radiotherapy alone for metastatic spinal cord compression from unfavorable tumors. Int J Radiat Oncol Biol Phys 2011;81:e861-868.

[59] Rades D, Douglas S, Huttenlocher S, Rudat V, Veninga T, Stalpers LJA, et al. Validation of a score predicting post-treatment ambulatory status after radiotherapy for metastatic spinal cord compression. Int J Radiat Oncol Biol Phys 2011;79:1503-6.

[60] Pichon B, Thillays F, Bourgier C, Mahé M-A, Supiot S. [Hypofractionated stereotactic radiotherapy of bone metastases]. Cancer Radiother J Soc Francaise Radiother Oncol 2014;18:342-9.

[61] Griffioen GHMJ, Toguri D, Dahele M, Warner A, de Haan PF, Rodrigues GB, et al. Radical treatment of synchronous oligometastatic non-small cell lung carcinoma (NSCLC): patient outcomes and prognostic factors. Lung Cancer Amst Neth 2013;82:95-102.

[62] De Ruysscher D, Wanders R, van Baardwijk A, Dingemans A-MC, Reymen B, Houben R, et al. Radical treatment of non-small-cell lung cancer patients with synchronous oligometastases: long-term results of a prospective phase II trial (Nct01282450). J Thorac Oncol Off Publ Int Assoc Study Lung Cancer 2012;7:1547-55.

[63] Koswig S, Budach V. [Remineralization and pain relief in bone metastases after after different radiotherapy fractions ( 10 times 3 Gy vs. 1 time 8 Gy). A prospective study]. Strahlenther Onkol Organ Dtsch Röntgenges Al 1999;175:500-8.

[64] Conway JL, Yurkowski E, Glazier J, Gentles Q, Walter A, Bowering G, et al. Comparison of patient-reported outcomes with single versus multiple fraction palliative radiotherapy for bone metastasis in a population-based cohort. Radiother Oncol J Eur Soc Ther Radiol Oncol 2016;119:202-7.

[65] Thariat J, Kirova Y, Milano G, Mornex F. [Combination of stereotactic irradiation and chemotherapy or targeted therapies: state of the art and preliminary recommendations]. Cancer Radiothérapie J Société Fr Radiothérapie Oncol 2014;18:270-9.

[66] Mirels H. Metastatic disease in long bones. A proposed scoring system for diagnosing impending pathologic fractures. Clin Orthop 1989:256-64.

[67] Hipp JA, Springfield DS, Hayes WC. Predicting pathologic fracture risk in the management of metastatic bone defects. Clin Orthop 1995:120-35.

[68] Fisher CG, DiPaola CP, Ryken TC, Bilsky MH, Shaffrey $\mathrm{Cl}$, Berven SH, et al. A novel classification system for spinal instability in neoplastic disease: an evidence-based approach and expert consensus from the Spine Oncology Study Group. Spine 2010;35:E1221-1229. 


\section{Table 1:}

Main indications and counter-indications of the different percutaneous treatments.

\begin{tabular}{|c|c|c|}
\hline \multicolumn{3}{|l|}{ Indications } \\
\hline Cementoplasty & \multicolumn{2}{|c|}{$\begin{array}{l}\text { - Uncontrolled pain by the analgesic drugs; } \\
\text { - Complication or poor tolerance of the opioid treatment } \\
\text { - Counter-indication to other methods (surgery, impossibility of radiation } \\
\text { therapy (RT) } \\
\text { - Analgesic alternative to other heavier methods such as surgical } \\
\text { treatment (for instance, acetabular cementoplasty) } \\
\text { - Combination for antalgic and/or stabilization with other local methods } \\
\text { such as analgesic RT or percutaneous thermal ablation. }\end{array}$} \\
\hline Thermal-ablation & \multicolumn{2}{|c|}{$\begin{array}{l}\text { - Pain relief for a bone metastasis with large extent in the soft-tissues } \\
\text { - Local control of a small bone metastasis } \\
\text { - Volume reduction for a large bone metastasis hardly accessible with } \\
\text { surgery or RT. }\end{array}$} \\
\hline Counter-indications & Absolute & Relative \\
\hline Cementoplasty & $\begin{array}{l}\text { - Unstable fracture } \\
\text { - Non located widespread pains } \\
\text { - Overall infection in progress or } \\
\text { cutaneous Infection at the } \\
\text { puncture site } \\
\text { - Severe coagulation disorders } \\
\text { - Allergy to the compound of the } \\
\text { cement }\end{array}$ & $\begin{array}{l}\text { - Asymptomatic fracture } \\
\text { - Breach of the posterior wall, } \\
\text { recoil of the posterior wall } \\
\text { (experience from the team) } \\
\text { - Radiculopathy } \\
\text { - Ductal extension of the tumour or } \\
\text { epiduritis } \\
\text { - Presence of an articular opening }\end{array}$ \\
\hline Thermal-ablation & $\begin{array}{l}\text { - Implanted electronic material } \\
\text { (pace-maker...) for monopolar } \\
\text { radiofrequency } \\
\text { - Orthopedic implants near the } \\
\text { ablation zone for monopolar } \\
\text { radiofrequency }\end{array}$ & $\begin{array}{l}\text { - "at risk" structure adjacent to the } \\
\text { ablation zone } \\
\text { - superficial lesion (risk of skin } \\
\text { burn) }\end{array}$ \\
\hline
\end{tabular}




\section{Table 2:}

Risk of radiosensibilisation with the different oncological treatments. Adapted from the French Society of Radiotherapy (SFRO) guidelines [65].

\begin{tabular}{|c|c|c|c|c|}
\hline Group & Drug & Guidelines & EBM level & Half-life and comment \\
\hline \multirow{3}{*}{$\begin{array}{l}\text { High-risk of } \\
\text { radiosensibilisation }\end{array}$} & Gemcitabine & $\begin{array}{l}4 \text { wks before RT } \\
4 \text { wks after RT }\end{array}$ & DGOS & $\begin{array}{l}\text { Depends on infusion duration: } \\
<1 \mathrm{hr}=>50 \mathrm{mn} \\
>1 \mathrm{hr}=>5 \text { to } 6 \mathrm{hrs}\end{array}$ \\
\hline & Doxorubicine & $\begin{array}{l}8 \text { days before RT } \\
8 \text { days after RT }\end{array}$ & Expert consensus & $36 \mathrm{hrs}^{*}$ \\
\hline & Bevacizumab & $\begin{array}{l}4 \text { wks before RT } \\
4 \text { wks after RT }\end{array}$ & Expert consensus & $\begin{array}{l}18 \text { days for women } \\
20 \text { days for men }\end{array}$ \\
\hline \multirow{5}{*}{ Compatible } & Carboplatin & No wash-out & Expert consensus & 5 days \\
\hline & Cisplatin & No wash-out & Expert consensus & $\begin{array}{l}\text { Cisplatin pharmacokinetic } \\
\text { results of the combination of } \\
\text { free and bound forms. Final } \\
\text { half-life is } 3 \text { to } 8 \text { days. }\end{array}$ \\
\hline & Vinorelbin & No wash-out & Expert consensus & $40 \mathrm{hrs}$ \\
\hline & Paclitaxel & No wash-out & Expert consensus & $19 \mathrm{hrs}$ \\
\hline & $\begin{array}{l}\text { Etoposide } \\
\text { Pemetrexed }\end{array}$ & No wash-out & Expert consensus & $6.4 \mathrm{hrs}$ ( 3 to $12 \mathrm{hrs}$ ) \\
\hline $\begin{array}{l}\text { Precaution } \\
\text { principle }\end{array}$ & $\begin{array}{l}\text { Erlotinib } \\
\text { Gefitinib } \\
\text { Docétaxel } \\
\text { Other targeted } \\
\text { therapies } \\
\text { Immunotherapies }\end{array}$ & \multicolumn{2}{|c|}{$\begin{array}{l}\text { No concomitant systemic oncological } \\
\text { therapy. } \\
\text { A delay of } 5 \text { half-lives between RT and } \\
\text { drug administration should be } \\
\text { respected (except with long half-life } \\
\text { treatments whose interruption is not } \\
\text { possible) }\end{array}$} & \\
\hline
\end{tabular}




\section{Table 3 :}

Mirels score $[66,67]$ for predicting fracture risk in the management of long bone metastases. Patients with a score $\leq 7$ should receive radiation therapy and patients with a score $\geq 9$ should receive prophylactic surgery. Patients with a score of 8 correspond to an intermediate group.

\begin{tabular}{|c|c|c|c|c|}
\hline \multicolumn{4}{|c|}{ Criteria } & \multirow{2}{*}{ Points } \\
\cline { 1 - 3 } Site of lesion & Size of lesion & Type of lesion & Pain & \\
\hline Upper limb & $<1 / 3$ of cortex & Blastic & Mild & 1 \\
\hline Lower limb & $1 / 3$ to $2 / 3$ of cortex & Mixed & Moderate & 2 \\
\hline Trochanteric region & $>2 / 3$ of cortex & Lytic & Functional & 3 \\
\hline \multicolumn{2}{|c|}{ Total } & & $/ 12$ points \\
\hline
\end{tabular}




\section{Table 4:}

Spinal Instability Neoplastic Score (SINS) for vertebrae stability evaluation [68]. Patients with a score of 0-6 are stable whereas the one with a score of $13-18$ are unstable. Patients with a score between 7 and 12 are intermediate.

\begin{tabular}{|c|c|c|}
\hline \multicolumn{2}{|r|}{ Item } & Points \\
\hline \multirow{4}{*}{ Location } & Transitions (C0-C2, C7-T2, T11-L1, L5-S1) & 3 \\
\hline & Mobile spine (C3-C6, L2-L4) & 2 \\
\hline & Semi-rigid spine (T3-T10) & 1 \\
\hline & Rigid spine (S2-S5) & 0 \\
\hline \multirow{3}{*}{ Mechanical pain } & YES & 3 \\
\hline & Non mechanical pain & 1 \\
\hline & None & 0 \\
\hline \multirow{3}{*}{ Type of lesion } & Lytic & 2 \\
\hline & Mixte & 1 \\
\hline & Condensing & 0 \\
\hline \multirow{3}{*}{ Alignment } & Subluxation/translation & 4 \\
\hline & Harmonious deformity & 2 \\
\hline & Normal & 0 \\
\hline \multirow{4}{*}{ Vertebral fracture } & $>50 \%$ & 3 \\
\hline & $<50 \%$ & 2 \\
\hline & Osteolysis $>50 \%$ (without vertebral fracture) & 1 \\
\hline & None & 0 \\
\hline \multirow[t]{3}{*}{ Posterior arc involvement } & Bilateral & 3 \\
\hline & Unilateral & 1 \\
\hline & None & 0 \\
\hline \multicolumn{2}{|r|}{ Total } & / 18 pts \\
\hline
\end{tabular}




\section{Figure 1:}

Sagittal MR T1-weigthed image (A) and axial CT-scanner image (B) showing an osteolytic metastasis of the patella infiltrating prepatellar soft-tissues and quadriceps tendon enthesis (white arrow) causing intense pain. C: Axial CT-scanner image during cryoablation treatment showing the cryode centering a round hypodense aspect filling the whole lesion and corresponding to the iceball. The procedure allowed immediate pain relief The patient had external radiotherapy consecutively and image D shows the follow-up CT-scanner performed 4 months later with re-ossification of the peripheral bone.

\section{Figure 2:}

Toward an integrative approach of bone metastases care in lung cancer.

\section{Supplemental 1:}

Composition of the French Reviewer Comity of the 2017-Lung Cancer South East French Guidelines 
Figure 1

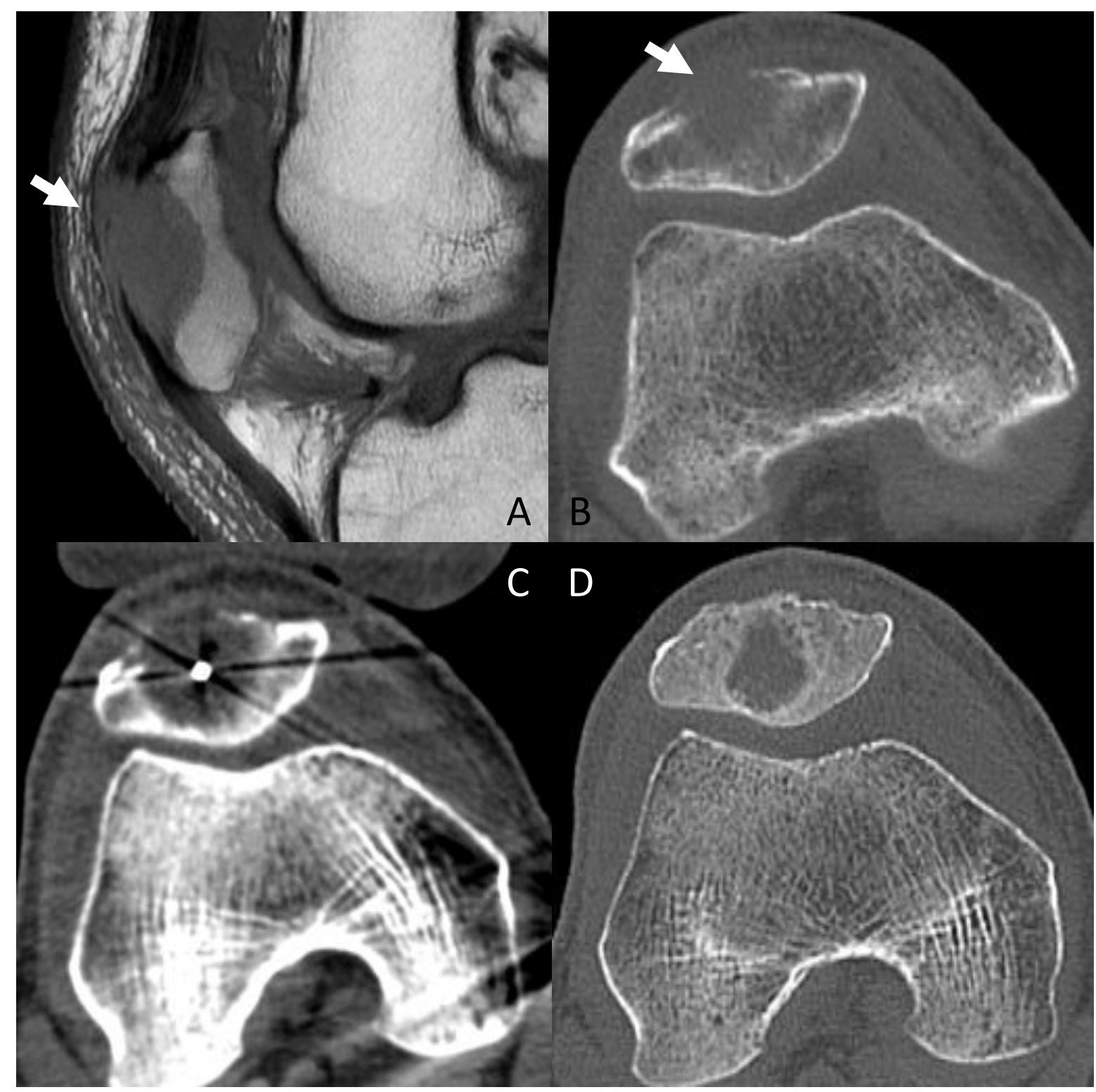


Step 1

Diagnosis of Bone extension

Identification of the different bone locations

\section{Step 2}

Diagnosis of Bone consequences for each location :

- Pain diagnosis

- Neurological diagnosis

- Fracture risk diagnosis

- Stability diagnosis

\section{Step 3}

Identification of the location requiring intervention and ranking of the priority

\section{Step 4}

\section{Discussion for each location of the available options}

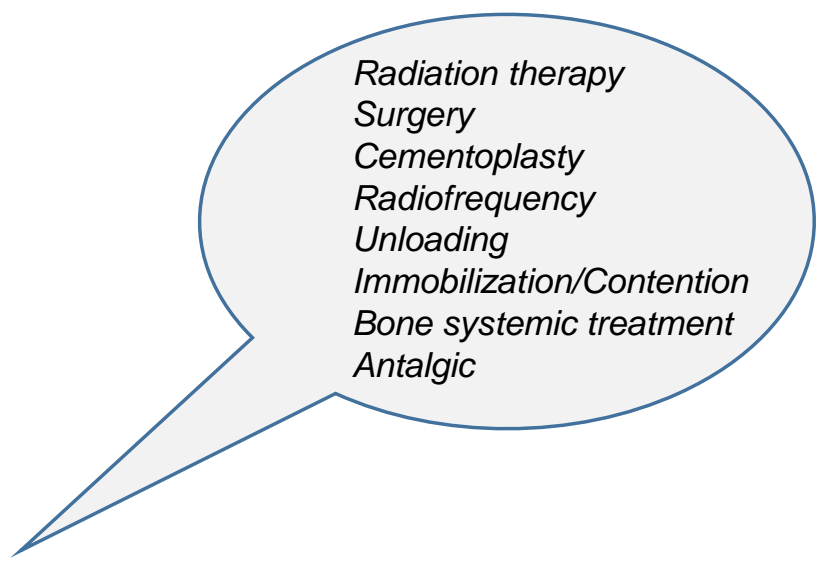

Collection of global oncological information from the oncologist and Multidisciplinary Tumor Board (MTB) :

- Histology

Step 5 - Molecular diagnosis, immune profile

- Kinetic of the tumor

- Anti-tumor strategy (chemotherapy, surgery, radiation therapy, immunotherapy, hormonal treatment)

- Toxicities of oncological treatments

\section{Patient status assesment:}

- Age and PS

- Vital functions: renal, liver, heart, lung and hematopoietic

\section{Step 6} function

- Cachexia: body weight loss, sarcopenia, energy metabolism, inflammation

- Dental status

- Patient wish

\section{Step 7}

Personnalized program of bone metastases management proposed by the Bone Metastatic Mutlidisciplinary Tumor Board - BM²TB- in conjunction with the oncologist and the MTB 